\title{
Introduction to the special issue "Sustainability Issues of Food Processing and Packaging: the Role of Life Cycle Assessment"
}

\author{
Carlo Ingrao $^{1} \cdot$ Amin Nikkhah $^{2} \cdot$ Jo Dewulf $^{3} \cdot$ Valentina Siracusa $^{4} \cdot$ Sami Ghnimi $^{2} \cdot$ Kurt A. Rosentrater $^{5}$
}

Published online: 14 April 2021

(c) The Author(s), under exclusive licence to Springer-Verlag GmbH Germany, part of Springer Nature 2021

\section{Introduction}

Food demand has increased globally with the increase in global population and will undoubtedly continue to increase in the medium-term future (Bajželj et al. 2014). It is well known that most of the food that is consumed worldwide is the result of a series of processing and packaging steps, prior to distribution and consumption. Food processing contributes some of the largest impacts associated with the entire food supply chain (SC), followed by logistics and packaging: these three steps together account for nearly half of the total energy consumed in the food systems (Monforti-Ferrario et al. 2015). Energy consumption during industrial food processing (from raw material preparation, acquisition and conversion to end-product treatment) encompasses several energy means such as heat (e.g. blanching, drying, preservation), electrical energy (conveyors, pumping), cooling (during processing or storage), lights and some others (Dalsgaard and Abbotts 2003).

Sustainable development of food SCs worldwide is dependent upon the importance that is given to reducing resource exploitation, energy consumption, material emissions and wastes and resultant environmental and

Carlo Ingrao

carlo.ingrao@unifg.it

1 Department of Economics, University of Foggia, Foggia, Italy

2 Department of Food Technology, Safety and Health, Faculty of Bioscience Engineering, Ghent University, Ghent, Belgium

3 Department of Green Chemistry and Technology, Faculty of Bioscience Engineering, Ghent University, Ghent, Belgium

4 Department of Chemical Science, University of Catania, Catania, Italy

5 Department of Agricultural and Biosystems Engineering, Iowa State University, Ames, USA socio-economic burdens. In recent years, scientific studies have shown that sustainability of food SCs is not always accomplished (Notarnicola et al. 2015): strategies are, therefore, urgently needed to maximise holistically integrated sustainable food SCs.

There exist several innovative technologies, like high-pressure processing, microwave heating, infrared heating, ohmic heating, ozone, power ultrasound, cold plasma and electrolysed water, which have been developed and investigated to date to test their technical feasibility for the processing of foods (Jermann et al. 2015). In addition to this, some of the novel, most widespread food-packaging technologies provide the use of active, biodegradable, intelligent and nanomaterial-based packages, as well as edible coatings and films (Fang et al. 2017). These are some of the currently available innovative and technologically advanced packaging solutions that enable preserving the quality and safety of the food contained, with low environmental impacts (Galluci et al. 2020). The literature so far indicates, however, that more environmental and socio-economic assessments have been developed in the production than in the processing and packaging of foods (Pardo and Zufía 2012; Valsasina et al. 2017). This emphasises upon further research being needed to explore the sustainability aspects associated with food processing and packaging: through this special issue, the guest editors wanted to contribute this field of research. After all, the assessment and improvement of the environmental issues associated with food packages' life cycles have become important priorities of the food packaging industry and are more and more at the centre of academic research worldwide (Siracusa et al. 2014; Ingrao et al. 2015a, b; Licciardello 2017): this was one good reason on the basis of this special issue development.

Food packaging generates two types of environmental impact: direct and indirect. The direct impact is caused by the production and end-of-life of the package entering the life cycle of the food that it is used for. The indirect impact, instead, is related to the influence that packaging has on the food's life cycle, mainly in terms of the generation and recovery of food waste (FW) (Molina-Besch et al. 2019). 
Food losses and wastes can be recycled into sustainable packaging materials in a circular economy (CE) perspective (Siracusa 2018), thereby reducing the utilisation of fossil-derived polymers and subsequent emissions of greenhouse gases that - as is well known and documented-affect climate change, and of other pollutants that impact upon human health and ecosystem quality.

In this regard, methodologies like life cycle assessment (LCA) and-more holistically speaking-life cycle sustainability assessment (LCSA) are quite valid for evaluation of those impacts, as well as of the social and economic repercussions. Over the years, those two methodologies have been documented to be very powerful tool to address trade-offs, both between life cycle stages and between different sustainability pillars (Traverso et al. 2012).

The International Journal of Life Cycle Assessment is quite familiar with the topic of sustainability of food processing and packaging and, in fact, a remarkable number of LCAs and LCSAs have been published thus far in the journal. This special issue aims at furthering the understanding and deepening of such a topic with special regard to product and process innovation, through expanded capability and greater ranges of the scenarios and systems analysed. It was designed to motivate researchers to address issues of novelty and scientific relevance in the assessment and improvement of sustainability in the food processing and packaging sector.

\section{Scope of this special issue}

This SI was developed around the belief that enhancing sustainability in the field of food processing and packaging can contribute to transitioning towards equitable, sustainable, post-fossil-carbon societies, as also highlighted by Ingrao et al. (2018). To be successful, the transition should be, however, envisioned, designed, tested, and implemented to ensure production, distribution, and consumption of food commodities that comply with the three sustainability dimensions.

In this context, this SI was set to attempt highlighting the importance of academic research to assess and stimulate holistically integrated sustainability of food processing and packaging systems. It is in this way that the SI could be the right platform for enhancement of knowledge on emerging methods, practical implementations, state-for-the-arts analyses, findings and lessons learned in such an important research content area.

\section{Overview of the papers included in this special issue}

The SI attracted interest and attention from the scientific community worldwide, with the collection of seven papers published between 2020 and 2021. The papers were submitted from several countries worldwide, but a total of 37 authors were overall involved in the development of those papers. They were from Italy, France, Denmark, Sweden, Japan and the USA (see Fig. 1) and were found by this editorial team as often belonging to institutions doing research in different but complementary subjects. This highlights that multidisciplinary perspectives are necessary to investigate sectors like food processing and packaging, as the research that needs to be done is often diversified and complex.

In their contributions, the authors explored relevant sustainability issues of food SCs, thereby enhancing the current state-of-the-art in the field. Most of them focussed upon packaging materials and technologies, as done by David et al. (2020), Del Borghi et al. (2020), Gallucci et al. (2020), Stefanini et al. (2020), and Yang and Rosentrater (2020), whilst Bianchi et al. (2020) and Sasaki et al. (2021) investigated the entire SC of foods with particular attention on the packaging factors that influence their environmental profiles.

All authors applied LCA, but made different methodological choices that were discussed in the following sections, where this SI's papers were reviewed based upon the respective investigated research field.

\subsection{Packaging materials and technologies}

Plastic continues to be increasingly produced as it is characterised by high levels of versatility, hygiene, flexibility and durability, which make it suitable for a wide range of applications: food packaging is one of those, mainly owing to the ability of plastic to best preserve foods (Stefanini et al. 2020). In this SI's paper collection, the environmental sustainability of food plastic packages was explored by David et al. (2020), Del Borghi et al. (2020) and Stefanini et al. (2020), also in comparison with alternative materials.

In their study, David et al. (2020) explored the environmental feasibility of reutilising Vine Shots (VSs) as natural fillers to be incorporated into polymer matrices. In particular, the authors carried out LCA to understand to what extent the usage of VS fillers makes packaging trays more environmentally sustainable than those produced for $100 \%$ virgin polymer. The authors carried out a comparative assessment between virgin plastics, like Poly(3-hydroxybutyrate-co-3-hydroxyvalerate) (PHBV), polylactic acid (PLA), and polypropylene (PP) and the same plastics filled with milled VSs.

The study highlighted that the two bioplastic matrices tested in the study, namely PLA and PHBV, exhibited higher environmental impacts than the fossil-based PP. David et al. (2020) believe that such a finding should be, however, tempered by the fact that PP-derived long-term impacts like plastic accumulation were not considered in their study, and that bioplastic production has not yet reached competitive 


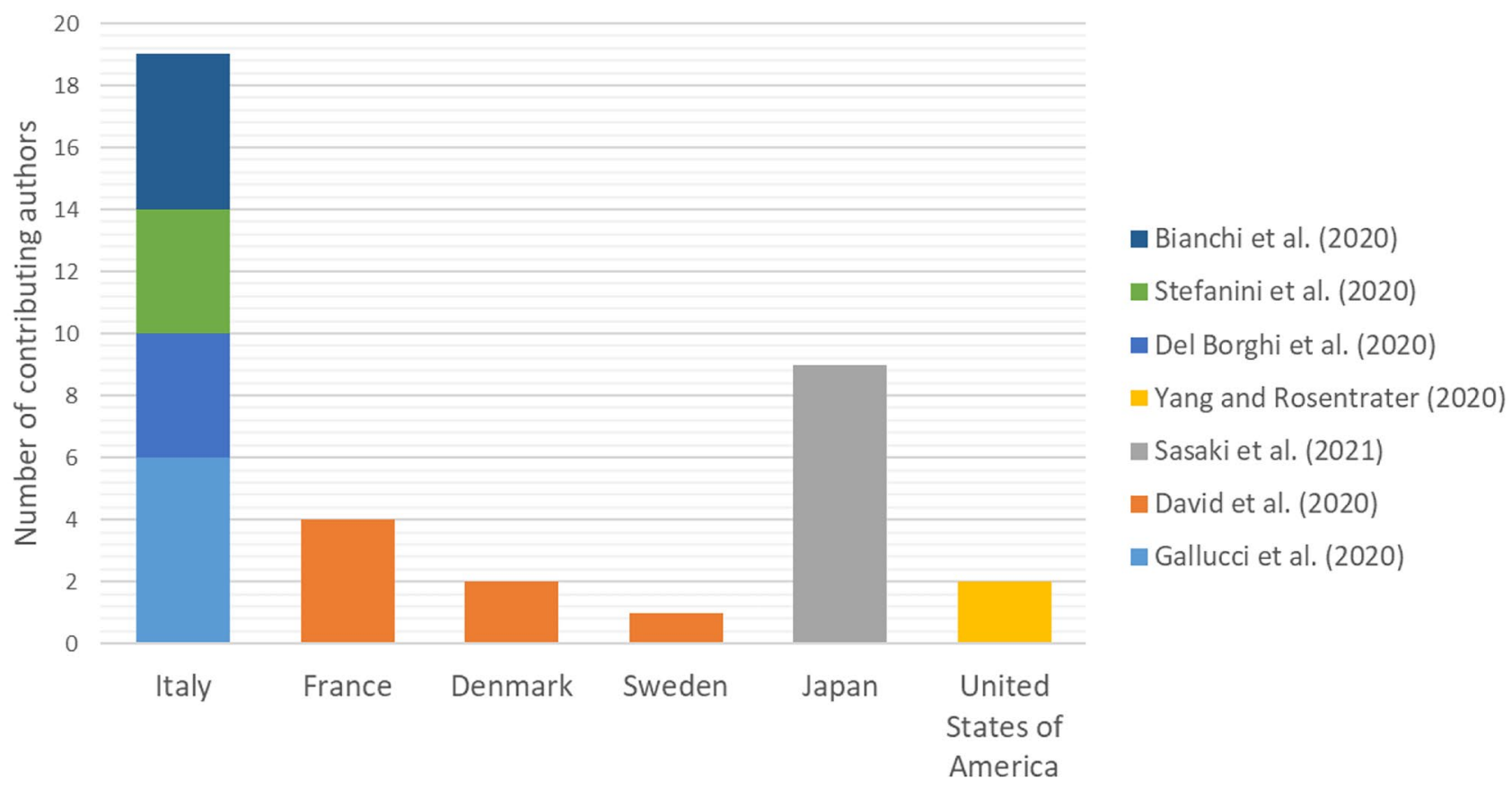

Fig. 1 Graphical distribution of the total of contributing authors of the seven papers

levels of technological advancements. In addition to this, the authors documented that the increase of VS particles as filler in plastic tray manufacturing resulted in environmental impact reduction, despite of the additional processing steps that were required for the VS filler production and of the higher VS filler density compared with the three polymeric matrices investigated. Through their study, David et al. (2020) documented, however, that there exists a $30 \%$ filling limit that needs to be taken into account not to compromise the quality and functionality of the investigated food-packaging tray. In this regard, the authors documented that $30 \%$ VS-filler content enables a $-8.5-19.9 \%$ reduction of the global warming potential (GWP) compared with the equivalent filler-less trays.

In line with Del Borghi et al. (2020), through their study, David et al. (2020) confirmed once again that food packaging is an evolving area, mainly because of the increasing introduction of sustainable innovative materials, products and technological solutions and of the continuous change in the consumption habits and lifestyle.

In this context, recently, there has been an upsurge in the interest for returnable packages from various industrial endusers like food and beverages, consumer goods and several others (Tua et al. 2019). The reuse of a product for the same initial purpose can significantly contribute to meeting the feature of slowing the resource loop provided by the circular economy, thus contributing to making products' life cycles more sustainable (Tua et al. 2019). The products' reusability principle can be highly beneficial for the packaging sector from both an economic and environmental perspective, especially for categories of reusable packages like pallets, crates, bottles and several others (Tua et al. 2019). This research content area was investigated by Del Borghi et al. (2020) who carried out a comparative LCA of different types of crates used for food delivery within the SC and made out of different materials: plastic, cardboard and wood. In addition to this, single- and multiple-use systems were considered and applied by the authors to disposable and reusable crates.

Based upon the main findings of the study, multiple-usage plastic crates environmentally perform best if the system provides a recovery step that allows for reusing crates many times, after a proper reconditioning treatment. In this regard, Del Borghi et al. (2020) assumed a 50-time reuse for the crates and, in line with Tua et al. (2019), documented that fewer reuses drastically reduce the environmental advantage of multiple-use crates, to the point that single-use crates that are sent to recycling and replaced with new ones would become preferable. Amongst the single-way crates, the solid wooden ones were proven to be less impacting in the majority of the selected impact categories. By contrast, the corrugated board crates highly affected the huge environmental impact associated with paper production and, for that, resulted in the less environmentally sound crates amongst the options considered by the authors.

Finally, Del Borghi et al. (2020) complemented the study with a sensitivity analysis that allowed them to understand that the transport network distances are critical issues, as they significantly affect the environmental sustainability of 
the crates, especially for the reusable ones. In this case, Del Borghi et al. (2020) indicated that those distances should be minimised the most possible without compromising the effectiveness of the collection/reconditioning/return system.

The food package return system was also explored by Stefanini et al. (2020), but in the case of bottles for the packing of pasteurised milk. In their study, the authors compared the environmental impacts of bottles made out of polyethylene (PET), R-PET, non-returnable glass and returnable glass (with eight use cycles), with the aim of understanding the most environmentally-friendly option.

Stefanini et al. (2020) highlighted that R-PET bottles were characterised by the best environmental profile mainly due to the avoided impacts deriving from the usage of the recycled PET. By contrast, the most impactful packaging solution was determined to be the non-returnable glass bottle. Better results were obtained using returnable glass bottles, though the authors interestingly documented that, even increasing the reuse-cycle number to 30 before the glass bottle is disposed of, the use of R-PET bottle remains the most preferable option. Agreeing with Stefanini et al. (2020), this should be attributed to the resultant virgin-plastic savings and to the lower energy consumption in the phases of production and transport of the R-PET bottles.

Through their study, Stefanini et al. (2020) emphasised upon the importance of investing in plastic recycling and in the usage of recycled plastics to contribute to reducing the pollution of seas and oceans and the damage to the maritime flora and fauna.

The field of hollow glass was investigated further by Gallucci et al. (2020) who applied LCA to evaluate the environmental performance of hollow glass used for the packing of foods and beverages by comparing a baseline scenario with a set of alternatives that were based upon using renewable energy, light-weighting, and by increasing the cullet percentage. The baseline scenario provided a $32 \%$ cullet content and the Italian energy mix as energy carrier. Two were then selected by the authors to be the alternative scenario: (1) increased cullet content up to $66 \%$ and (2) scenario 1 plus a $5 \%$ light-weighting and the use of a photovoltaic plant to supply $100 \%$ of the electricity requirements. The study allowed Gallucci et al. (2020) to understand that scenario 2 is the most environmentally sustainable for all the midpoint indicators considered by the authors. Such a finding puts further evidence upon the benefits of increasing - to the possible limit - the use of recycled materials in replacement of the virgin counterparts in a CE perspective, and of using renewable carriers for supply of the process energy requirements. The combined application of both improvements clearly amplifies the environmental gains compared with the baseline scenario.

There is increasing environmental concern on the use of petroleum-based products, so that consumers and governments have recently shown much interest in their replacement with more sustainable alternatives.

More and more scientific studies are being done to examine environmental and sustainability-related aspects of raw materials as well as finished goods and, under this perspective, some bio-based products may be promising as they appear to have lower environmental footprints. Yang and Rosentrater (2020) investigated this field of research by evaluating the potential environmental savings of glycerolbased structural bio-adhesives usable also in food packaging applications, produced the reversible addition-fragmentation chain transfer polymerization processing. For the study development, a cradle-to-gate LCA was performed to compare the following two pathways for glycerol production: bio-glycerol produced from biodiesel manufacturing vs. petroleum-based glycerol derived from petroleum refineries. Several environmental impact categories were considered by the authors, along with the effects of using different allocation strategies (i.e. energy content, mass value and economic value).

Based upon results from this study, bio-based glycerol structural adhesives exhibited a lower environmental impact in general compared with petro-glycerol-based counterparts. Higher environmental impacts throughout the structural bioadhesive life cycle were, however, observed by adopting the energy allocation method, mainly because of key factors like the electricity sources for manufacturing and the resulting product yields. The study provided an information pack that could serve as a useful guide to examine and develop biomaterials and processes. The authors recommended, however, to further explore additional potential approaches that enable reducing environmental issues like the carbon intensity and eutrophication potential in the polymerisation process, as the latter was determined to be a key hotspot of structural bio-adhesive production. Reducing those issues by operating on this system development step could yield substantial environmental impact reductions as this process becomes widely deployed in industry.

Table 1 provides a summary of the characteristics of the articles reviewed in this section, in terms of system parameters, output products, system boundaries, functional units (FUs) and issues related to the impact assessment methodologies used

All authors applied LCA according to the International Standards ISO 14040-44 (ISO 2006a, b), with Del Borghi et al. (2020) and Gallucci et al. (2020) following also the PCRs for the types of packaging product they have investigated. In line with the literature currently available on the subject, through this SI's paper collection, LCA was proven to be a holistic, scientifically valid tool to be largely suitable to assess-and to find measures to reduce-the environmental impact and damage in the packaging sector. 


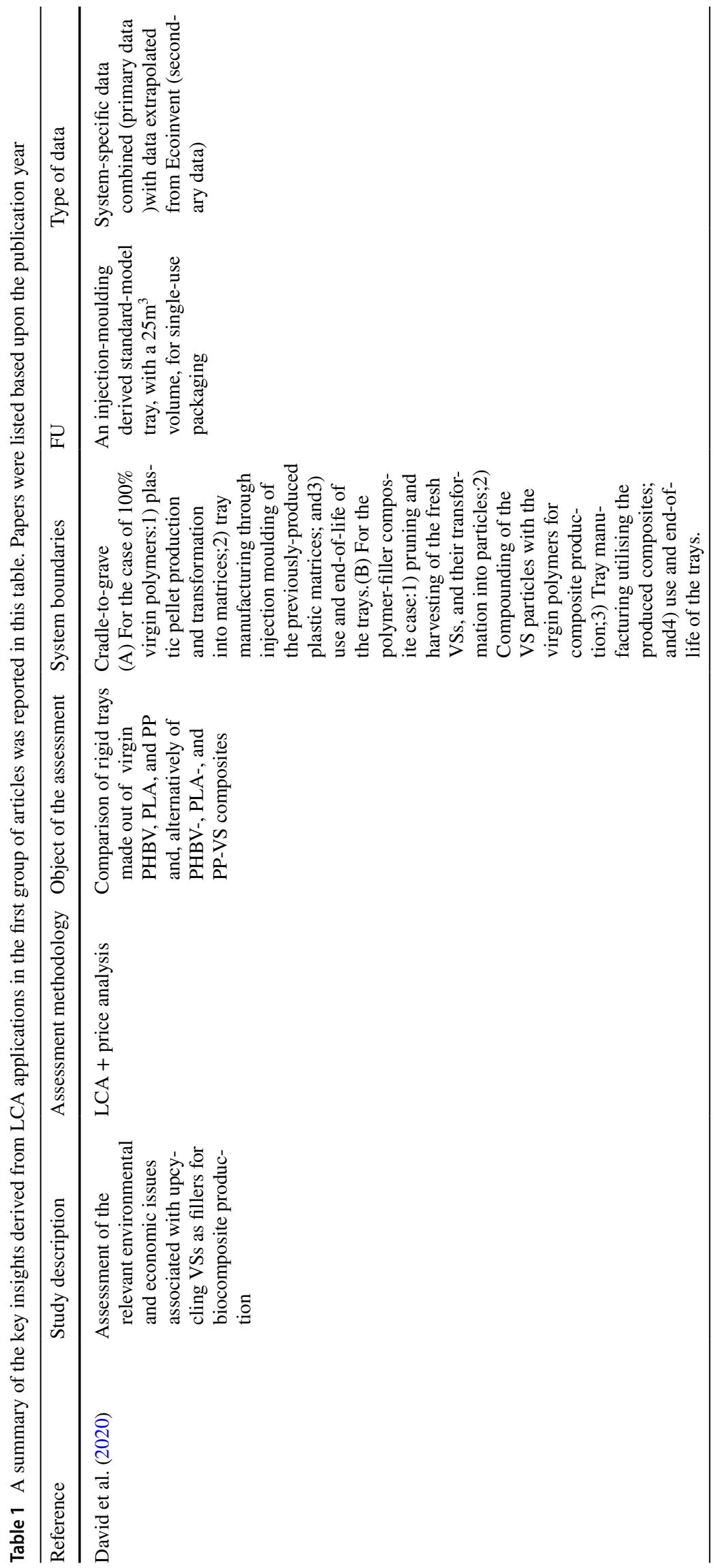




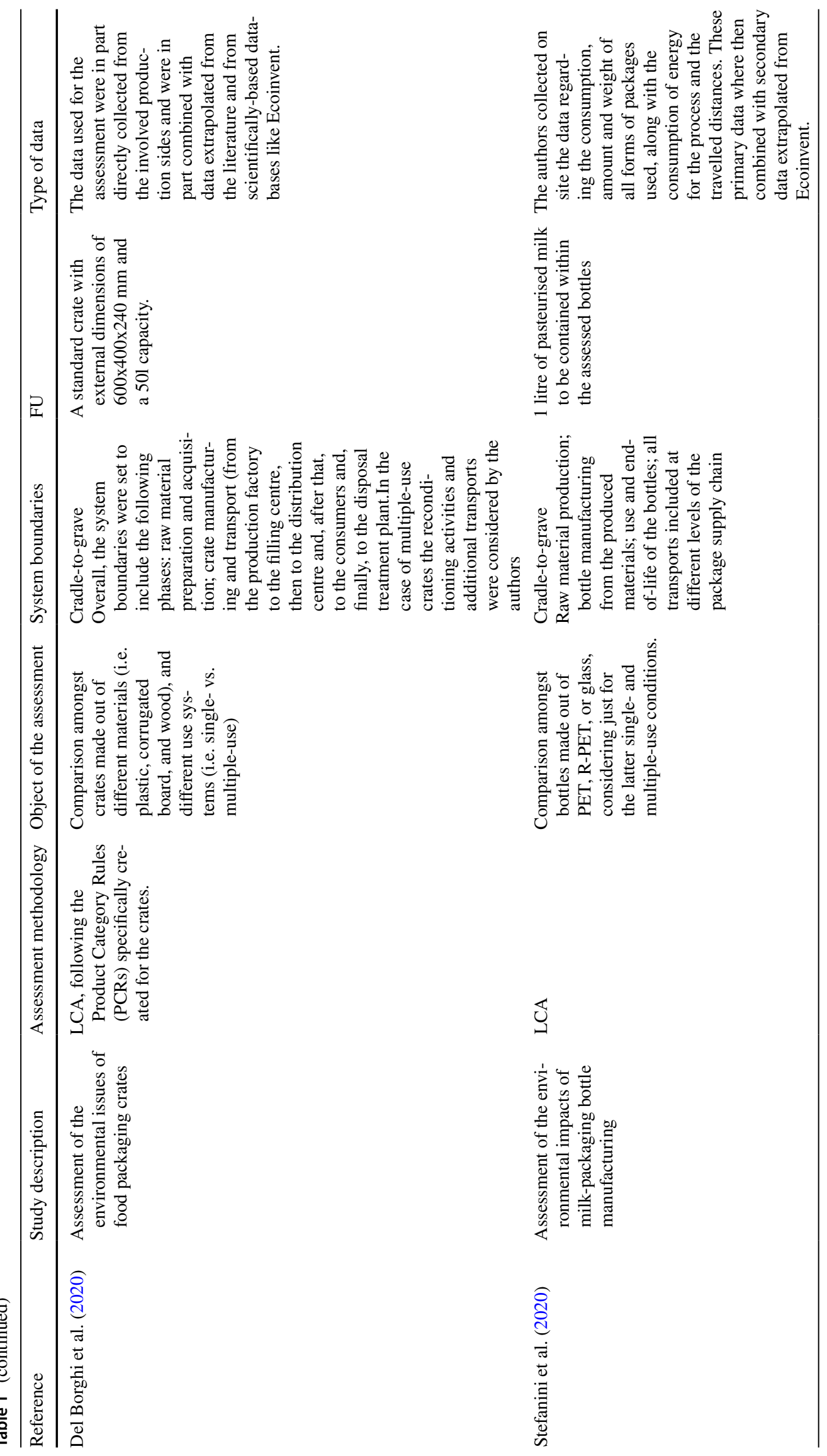




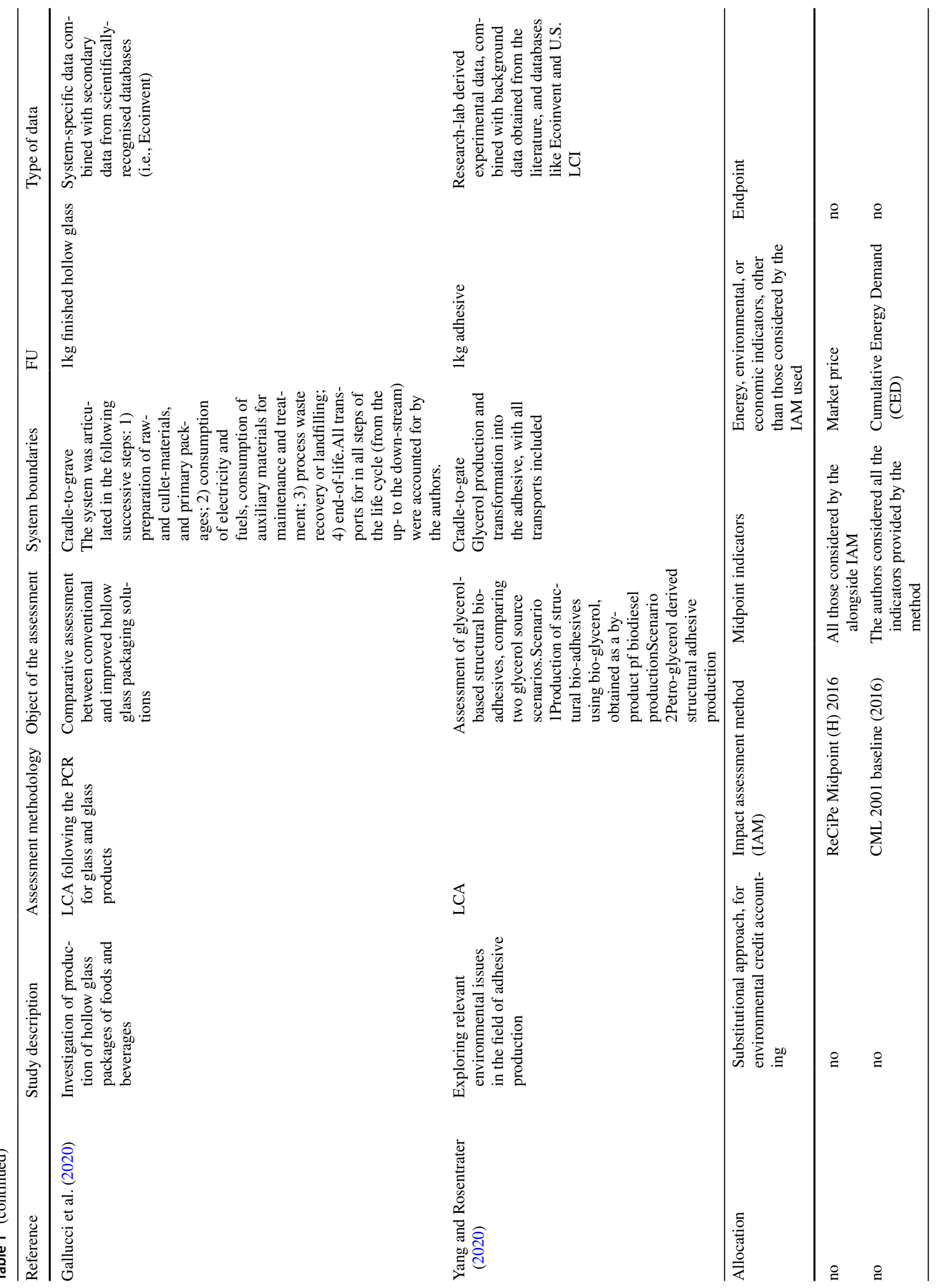




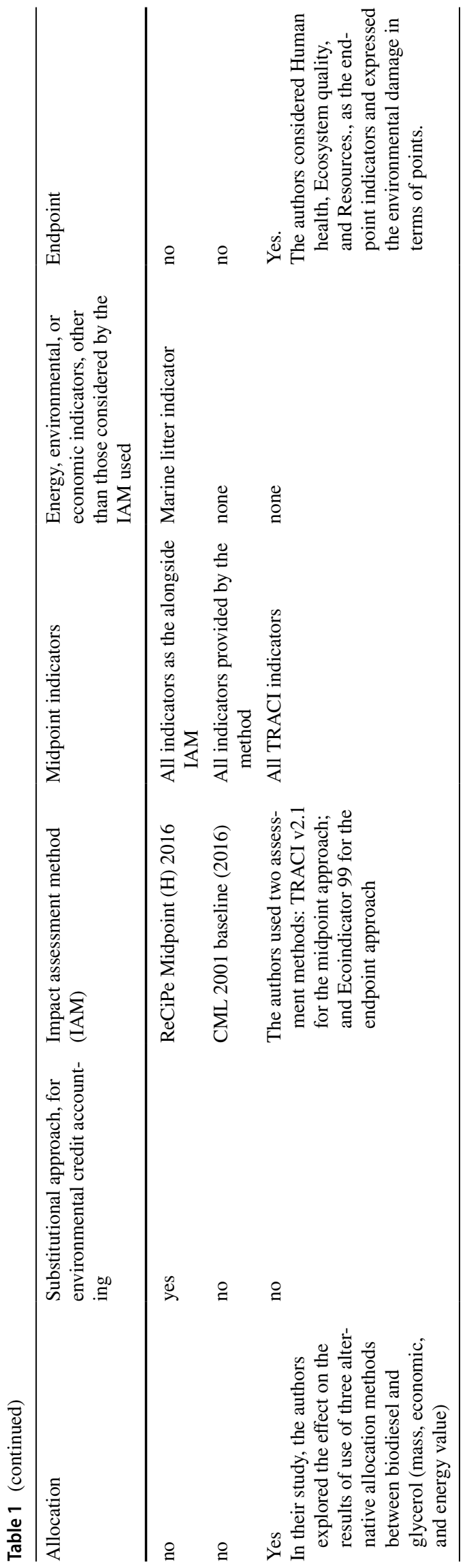

In addition to this, from the review of those five articles, it was understood that LCA is effective as an environmental comparison tool of materials and technologies, as well as of methodological issues as done by Yang and Rosentrater (2020) for the allocation criterion.

As regards the FUs and the system boundaries, those were found by this guest editorial team to be consistent with the aims and scopes of the studies and be representative of the functions of the systems investigated. From Table 1, it can be observed that all FUs refer to the produced package, with exception of Stefanini et al. (2020) in which it was represented by the contained beverage. In all papers, but Yang and Rosentrater's (2020), the system boundaries were of the cradle-to-grave type and encompassed all steps from the preparation and acquisition of the material and energy inputs to the end-of-life of the produced package. By contrast, Yang and Rosentrater (2020) stopped the assessment at the exit gate of the university lab where the adhesives have been developed, tested, and environmentally assessed.

Moreover, allocation and substitution are key issues in the current international debate on LCA application practices: as shown in Table 1, those were applied just by Yang and Rosentrater (2020) and Stefanini et al. (2020), respectively.

All authors, instead, carried out their environmental assessment with a midpoint approach, with only Yang and Rosentrater (2020) extending it to the endpoint approach, that is, the environmental damage was accounted for and was expressed in the form of points. Two were essentially the most used impact assessment methods in these studies:

-Recipe Midpoint (H) 2016, by David et al. (2020) and

Stefanini et al. (2020); and

-CML 2001 baseline 2016, by Del Borghi et al. (2020) and Gallucci et al. (2020), as established by the PCRs.

Differently, Yang and Rosentrater (2020) applied the TRACI method for the midpoint assessment and the Ecoindicator 99 for the endpoint one.

\subsection{Packaging as one phase of food supply chains}

In this section, the guest editors reviewed the papers that modelled packaging as one key phase of any food supply chain.

In their study, Bianchi et al. (2020) reported upon the findings from a comparative LCA of dark, milk and white chocolate with a cradle-to-grave approach, to detect the most environmentally burdening chocolate ingredients and production phases. According to the authors, chocolate can be found on the market in the form of bars wrapped by several possible materials that, however, must preserve intact the quality and the aroma of chocolate. In their study, the authors compared three different types of package: sole PP 
or aluminium film as primary package with cardboard or Kraft paper as secondary package.

Through their study, the authors documented that the phases to be most responsible for the environmental impact associated with chocolate's life cycle are the production of all dairy and cocoa derivatives. Agreeing with Bianchi et al. (2020), improvements in this regard could be achieved through more sustainable systems of production and processing. In addition to this, the authors documented that changes in the ingredients, acting upon their amounts and/or types, are not feasible as they would alter chocolate's important features. So, they found that considerable improvements can be obtained by selecting the PP layer as packaging system, as it resulted from the authors' analysis to be the least impacting packaging solution.

Another sector in which packaging plays multiple key roles is that of the fruits and vegetables $(\mathrm{F} \& \mathrm{~V})$ as it can contribute to preserving the generation of food losses during transportation due to vibration and shock-derived damage. The manufacturing of advanced packaging systems to better protect $\mathrm{F} \& \mathrm{~V}$ and reduce those losses may end up worsening the environmental profile associated with the $\mathrm{F} \& \mathrm{~V}$ life cycle due to the use of additional, often more sophisticated materials and of additional energy (Sasaki et al. 2021). Such a relevant research field was interestingly investigated by Sasaki et al. (2021) who focussed upon fresh peaches and carried a full LCA to evaluate both the positive and the negative influences that packaging plays upon their life cycle.

Two packaging scenarios were considered, which provided the use of cardboard box but with the difference that, whilst in the baseline scenario, peaches are placed as such within the box without using any caution materials (unprotected fruits), in the improved scenario, they are wrapped by a sheet and then a foam net (protected conditions) with both of them being made out of expended polyethylene (EPE).

In addition to this, the authors accounted for a set of distances in the range $0-2000 \mathrm{~km}$ for transporting the peaches from the cultivation farm to a fruit sorting facility, then to the wholesale market and, after that, to the retailer. Peach cultivation was considered by the authors because, though the number of transported peaches is the same in both packaging scenarios (15), the overall weight of the implied peaches was determined by Sasaki et al. (2021) to be $1-1.21 \mathrm{~kg}$ for the protective package, and $2.50-10 \mathrm{~kg}$ for the non-protective package. This is because additional peaches are required to compensate the losses due to vibration and shocking during transportation: this occurs much more when they are transported unprotected. In this case, in fact, the authors have interestingly documented that the peach damage fraction can increase up to $90 \%$ for a $2000 \mathrm{~km}$ travelled distance, which means that the peaches must be almost entirely replaced. By contrast, in case of protective package use, the losses were calculated by the authors to be largely lower, with a maximum of $17.33 \%$ for a $2000 \mathrm{~km}$ transport distance.

Overall, the study highlighted that, though being more sophisticated, the protective package is more environmentally sustainable than the non-protective one, with impact categories like climate change and resource depletion being reduced by up to around $94 \%$. According to the authors, the greatest benefit of the protective package stays in the substantial reduction of the peach losses during transportation and, in turn, of the amount of additional peaches that need to be cultivated to replace those lost during delivery.

As done for the previous group of papers, Table 2 summarises the main findings from the two papers discussed thus far.

From the table, it is understood that those two studies investigated the supply chain of different-category foods: sweets (Bianchi et al. 2020) and fruits (Sasaki et al. 2021). Both studies applied-and, in line with previous five published in this SI, remarked the scientific validity and usefulness of - LCA, with the difference that, similarly to Del Borghi et al. (2020), Bianchi et al. (2020) followed also the specialised PCRs besides the ISO (2006a, b).

Another similar aspect that is worth being mentioned is that the two studies either chose the output food product in unitary amount (i.e. $1 \mathrm{~kg}$ ) as FU, which is a quite widespread practice that makes LCAs more easily comparable to each other. Stefanini et al. (2020) did the same in their study on pasteurised milk packaging, choosing $1 \mathrm{~L}$ produced milk as FU. Even the system boundaries were found by this guest editorial team to be comparable, with both of them being of the cradle-to-grave type and including all key production and transportation stages in the life cycles of the investigated foods.

The allocation issue of multi-output processes like the cocoa one in which cocoa butter is the core product and is co-produced with cocoa powder and liquor was addressed by Bianchi et al. (2020) through performing a mass-based allocation. As done by Yang and Rosentrater (2020), Bianchi et al. (2020) carried out a methodology-based sensitivity analysis to determine the change in the results when another allocation method is used.

Finally, similarly to Del Borghi et al. (2020) and Gallucci et al. (2020), Bianchi et al. (2020) followed a midpoint approach and used the CML methods as established by the PCRs they applied; by contrast, as done by Yan and Rosentrater (2020), Sasaki et al. (2021) expanded the assessment to the endpoint approach, using the LIME method. 







\section{Conclusions}

The SI attained the aim of collecting selected relevant studies to address sustainability issues associated with food processing and packaging. Under this perspective, in line with literature studies like Licciardello (2017), the SI further contributed to the awareness that those two phases can largely contribute to the environmental impact of food supply chains and life cycles; therefore, improvement and advancement are needed to make those two phases as sustainable as possible.

This overview of the paper revealed that the midpoint approach continued to be the preferred one, with indicators like global warming potential, ozone layer depletion, photochemical oxidation, eutrophication and acidification, ecotoxicity, water depletion and abiotic depletion, being considered quite representative of the environmental profiles of food processing and packaging systems.

Finally, all articles included in this SI were characterised by a clear discussion of the key features and contributions of the researches, which were carried out with a focus on practical applications beyond theoretical discussions. This made those articles even more effective in advancing the knowledge on the subject, and confirmed that reliable LCAs should rely upon the proper combination of primary and secondary data. Findings from those LCAs can then be generalised, projected to the future and used as the starting point to develop long-term best practices.

Finally, the significant response to this SI can be considered to be particularly encouraging, as it proves once again that academic communities keep on doing relevant research for enhanced sustainability of food supply chains and life cycles.

Acknowledgements Prof. Carlo Ingrao, as the Managing Guest Editor of this SI, would like to convey his most heartfelt gratitude to his guest editors because, without their supportive commitment and work, this SI would have not been possible. In addition to this, the whole guest editorial board would like to thank the authors for the high quality of the manuscripts they have contributed. The relevant work they have developed will make this paper collection be a valid tool to spread knowledge on ways to achieve sustainability in the phases of processing and packaging within the life cycles of foods. Finally, special thanks are conveyed to Prof. Dr. Matthias Finkbeiner (Esteemed Editor-inChief of the Journal), along with Mr. Jesson Austria (Journal's Editorial Office Assistant) for having supported, guided and supervised the development of this SI project since the very beginning of its conception.

\section{References}

Bajželj B, Richards KS, Allwood JM, Smith P, Dennis JS, Curmi E, Gilligan CA (2014) Importance of food-demand management for climate mitigation. Nat Clim Chang 4(10):924
Bianchi FR, Moreschi L, Gallo M, Vesce E, Del Borghi A (2020) Environmental analysis along the supply chain of dark, milk and white chocolate: a life cycle comparison. Int J Life Cycle Assess https://doi.org/10.1007/s11367-020-01817-6

Dalsgaard H, Abbotts W (2003) 8-Improving energy efficiency. In: Mattsson, B., Sonesson, U. (Eds.), Environmentally-friendly Food Processing. Woodhead Publishing 116-129

David G, Croxatto Vega G, Sohn J, Nilsson AE, Hélias A, Gontard $\mathrm{N}$, Angellier-Coussy H (2020) Using life cycle assessment to quantify the environmental benefit of upcycling vine shoots as fillers in biocomposite packaging materials. Int $\mathrm{J}$ Life Cycle Assess https://doi.org/10.1007/s11367-020-01824-7

Del Borghi A, Parodi S, Moreschi L, Gallo M (2020) Sustainable packaging: an evaluation of crates for food through a life cycle approach. Int J Life Cycle Assess https://doi.org/10.1007/ s11367-020-01813-w

Fang Z, Zhao Y, Warner RD, Johnson SK (2017) Active and intelligent packaging in meat industry. Trends Food SciTechnol 61:60-71

Gallucci T, Lagioia G, Piccinno P, Lacalamita A, Pontrandolfo A, Paiano A (2020) Environmental performance scenarios in the production of hollow glass containers for food packaging: an LCA approach. Int J Life Cycle Assess. https://doi.org/10.1007/ s11367-020-01797-7

Ingrao C, Bacenetti J, Bezama A, Blok V, Goglio P, Koukios EG, Lindner M, Nemecek T, Siracusa V, Zabaniotou A, Huisingh D (2018) The potential roles of bio-economy in the transition to equitable, sustainable, post fossil-carbon societies: findings from this virtual special issue. J Clean Prod 204:471-488

Ingrao C, Lo Giudice A, Bacenetti J, MousaviKhaneghahde Souza Sant'Ana, A., Rana, R., Siracusa, V., A (2015a) Foamy polystyrene trays for fresh-meat packaging: a life-cycle inventory data collection and environmental impact assessment. Food Res Int 76:418-426

Ingrao C, Tricase C, Cholewa-Wójcik A, Kawecka A, Rana R, Siracusa V (2015b) Polylactic acid trays for fresh-food packaging: a carbon footprint assessment. Sci Total Environ 537:385-398

ISO (International Organization for Standardization) (2006a) 14040-Environmental Management - Life Cycle Assessment Principles and Framework

ISO (International Organization for Standardization) (2006b) 14044-Environmental Management - Life Cycle Assessment Requirements and Guidelines

Jermann C, Koutchma T, Margas E, Leadley C, Ros-Polski V (2015) Mapping trends in novel and emerging food processing technologies around the world. Innov Food SciEmergTechnol 31:14-27

Licciardello F (2017) Packaging, blessing in disguise. Review on its diverse contribution to food sustainability. Trends Food SciTechnol 65:32-39

Molina-Besch K, Wikström F, Williams H (2019) The environmental impact of packaging in food supply chains - does life cycle assessment of food provide the full picture? Int J Life Cycle Assess 24:37-50

Monforti-FerrarioDallem JF, Pinedo Pascua I, Motola V, Banja M, Scarlat N, Medarac H, Castellazzi L, Labanca N, Bertoldi P, Pennington D, Goralczyk M, Schau E, Saouter E, Sala S, Notarnicola B, Tassielli G, Renzulli PAF (2015) Energy Use in the EU Food Sector: State of Play and Opportunities for Improvement. Publications Office of the European Union, European Union

Notarnicola B, Tassielli G, Renzulli PA, Giudice AL (2015) Life Cycle Assessment in the agri-food sector: an overview of its key aspects, international initiatives, certification, labelling schemes and methodological issues. In: Notarnicola B, Salomone R, Petti L, Renzulli PA, Roma R, Cerutti AK (Eds.), Life Cycle Assessment in the Agri-food Sector. Springer International Publishing 1-56 
Pardo G, Zufía J (2012) Life cycle assessment of food-preservation technologies. J Clean Prod 28:198-207

Sasaki Y, Orikasa T, Nakamura N, Hayashi K, Yasaka Y, Makino N, Shobatake K, Koide S, Shiina T (2021) Life cycle assessment of peach transportation considering trade-off between food loss and environmental impact. Int J Life Cycle Assess https://doi.org/10. 1007/s11367-020-01832-7

Siracusa, V., 2018. Food Waste for Sustainable Packaging Materials. In: Reference Module in Materials Science and Materials Engineering. p. 1-9 AMSTERDAM: Elsevier Sci. Publ. B.V., ISBN: 9780128035818; doi: https://doi.org/10.1016/B978-0-12-8035818.10529-6

Siracusa V, Ingrao C, Lo Giudice A, Mbohwa C, Dalla Rosa M (2014) Environmental assessment of a multilayer polymer bag for food packaging and preservation: an LCA approach. Food Res Int 62:151-161

Stefanini R, Borghesi G, Ronzano A, Vignali G (2020) Plastic or glass: a new environmental assessment with a marine litter indicator for the comparison of pasteurized milk bottles. Int J Life Cycle Assess. https://doi.org/10.1007/s11367-020-01804-X

Traverso M, Finkbeiner M, Jørgensen A, Schneider L (2012) Life cycle sustainability dashboard. J IndEcol 16(5):680-688

Tua C, Biganzoli L, Grosso M, Rigamonti L (2019) Life cycle assessment of reusable plastic crates (RPCs). Resources 8(2):110

Valsasina L, Pizzol M, Smetana S, Georget E, Mathys A, Heinz V (2017) Life cycle assessment of emerging technologies: the case of milk ultra-high pressure homogenisation. J Clean Prod 142:2209-2217

Yang M, Rosentrater KA (2020) Cradle-to-gate life cycle assessment of structural bio-adhesives derived from glycerol. Int J Life Cycle Assess https://doi.org/10.1007/s11367-020-01733-9

Publisher's Note Springer Nature remains neutral with regard to jurisdictional claims in published maps and institutional affiliations. 